\title{
Detection of Several Carbohydrates Using Boron-doped Diamond Electrodes Modified with Nickel Hydroxide Nanoparticles
}

\author{
Milena E. Teixeira, Graziela C. Sedenho, and Nelson R. Stradiotto ${ }^{\dagger}$ \\ Department of Analytical Chemistry, Institute of Chemistry, Universidade Estadual Paulista (UNESP), Rua \\ Prof. Francisco Degni, 55, Araraquara, 14800-060, Brazil
}

\begin{abstract}
In this work the electrooxidations of glucose, galactose, mannose, rhamnose, xylose and arabinose are studied at a nickel hydroxide nanoparticle modified boron-doped diamond electrode and compared to an unmodified electrode. These carbohydrates are very important in the second-generation ethanol production process. Nickel hydroxide modified borondoped diamond was characterized by scanning electron microscopy and energy dispersive X-ray. Electrochemical impedance spectroscopy was employed to study the interface properties of surface-modified electrodes in the absence and presence of the carbohydrates. Limits of detection were $5.3 \times 10^{-5}, 6.8 \times 10^{-5}, 2.7 \times 10^{-4}, 6.9 \times 10^{-5}, 8.8 \times 10^{-5}$ and $2.6 \times 10^{-5} \mathrm{~mol} \mathrm{~L}^{-1}$ for glucose, galactose, mannose, rhamnose, arabinose, xylose, respectively.
\end{abstract}

Keywords Carbohydrates, nickel nanoparticles, modified boron-doped diamond electrode, voltammetry

(Received March 17, 2015; Accepted April 21, 2015; Published August 10, 2015)

\section{Introduction}

The search for new materials with electrocatalytic characteristics and the study of their applications such as a fuel cell catalyst, ${ }^{1-5}$ electrocatalyst for organic synthesis ${ }^{6-8}$ and in analytical approaches $^{9}$ have received considerable interest in recent years. In electroanalysis, electrocatalytic materials have been used as a modifier of electrodes for the development of sensors and detectors for organic and inorganic compounds due to their superior properties, which are significantly different from conventional electrodes, e.g., glassy carbon, boron doped diamond (BDD) or platinum. There are several types of materials with electrocatalytic properties used as an electrode modifier, among them enzymes and DNA ${ }^{10,11}$ in biosensors and metal and metal oxide nanoparticles (NPs), for example, for determination of inorganic ${ }^{12,13}$ and organic compounds. ${ }^{14-17}$ The electrode modification with metal or metal oxide NPs increases surface coverage and catalytic activity of the electrode. With a greater number of active sites there is considerable improvement in the signal-to-noise ratio, and the modification requires minimal amounts of modifying materials which reduces the cost of electrode preparation. Thus, these properties make nanomaterials suitable for electroanalytical applications. ${ }^{18}$ Metals commonly used for NPs are gold, silver, and platinum, but also metals such as palladium, ruthenium, nickel, copper, bismuth and iridium are used.

Several studies have been devoted examining the electrocatalytic potential of nickel in several applications. Nickel nanoparticles (NiNPs), in the form of hydroxide or oxide, have been utilized in the study of oxygen-evolution reactions, ${ }^{19,20}$ oxygen reduction reactions ${ }^{21}$ and the oxidation of

$\dagger$ To whom correspondence should be addressed.

E-mail: nrstradi@iq.unesp.br organic compounds, such as glucose, alcohol, amino acids, ascorbic acid, neurotransmitters and drugs, ${ }^{14,22-30}$ and inorganic compounds. ${ }^{12,31}$ Especially in the determination of glucose, nickel modified electrodes have been extensively studied mainly in biological samples and have shown to be a good alternative to enzymic sensors, which in spite of showing great selectivity and high sensitivity, are thermally and chemically unstable. Nickel hydroxide or oxide NPs exhibit remarkable electrocatalytic capability for glucose oxidation and other compounds due to the effect originating from the redox couple of $\mathrm{Ni}(\mathrm{OH})_{2} / \mathrm{NiO}(\mathrm{OH})$ on the electrode surface in as alkaline medium. ${ }^{27,28,32-43}$

Surface modification with NiNPs can be done by various chemical routes, such as sol-gel, electrodeposition and electrophoretic deposition, among others. Among them, electrodeposition is convenient because it involves the direct formation of NPs on the electrode surface. In addition to be a simple technique, electrodeposition may occur at room temperature and is possible to control size and coverage of electrodeposited nanostructures by monitoring deposition parameters such as deposition time, deposition potential and metallic ion concentration. ${ }^{44}$

Furthermore, the choice of the substrate electrode is important because interaction between NPs and the electrode surface must be favored, background current must be low and the material has to show good electrical conductivity and physical robustness. Many substrates have been already used for NiNP modification, such as $\mathrm{BDD},{ }^{22,33}$ glassy carbon, ${ }^{34,35}$ graphene, ${ }^{37-40}$ polymer modified electrodes, ${ }^{41,43}$ carbon nanotube, ${ }^{27}$ graphite, ${ }^{42} \mathrm{TiO}_{2}$ nanowire electrode, ${ }^{28}$ as well as gold. ${ }^{32}$ Among them, BDD is attractive because it shows many required features, and it is stable in a wide potential window, shows low chemical reactivity, it is resistant in various corrosive solutions and is also an excellent platform to promote nanoparticle formation instead of films due to the irregularity of its surface..$^{33,45}$

In this study we have associated the ability of NiNP to oxidize 
carbohydrates with the fact that BDD has attractive features as an electrode and provides the easy formation of NPs. The great majority of past research has focused on glucose oxidation, and to our knowledge, few works have studied other carbohydrates, like sucrose, xylose, lactose, fructose, maltose, arabinose and rhamnose. ${ }^{17,44,46-49}$ Recently, our group studied the kinetics of electrooxidation of different carbohydrates at a glassy carbon electrode modified with carbon nanotubes decorated with nickel oxy-hydroxide. ${ }^{17}$ A our interest is to study the electroanalytical response of several carbohydrates at BDD modified with nickel hydroxide for future determination of these carbohydrates in lignocellulosic material of sugar cane, which are important in the second-generation ethanol production. ${ }^{50,51}$ Therefore, the main goal of the present paper is the fabrication and the characterization of BDD electrodes modified with nickel hydroxide nanoparticles $\left(\mathrm{Ni}(\mathrm{OH})_{2} / \mathrm{BDD}\right)$ and its use in the electrooxidation of glucose, galactose, mannose, rhamnose, arabinose and xylose, the main carbohydrates present in the lignocellulosic material of sugar cane.

\section{Experimental}

\section{Reagents and chemicals}

All reagents used in this study were of analytical grade and all solutions were prepared using water from the Milli-Q system at a resistivity no less than $18.2 \mathrm{M} \Omega \mathrm{cm}^{-1}$ at $25^{\circ} \mathrm{C}$. The electrochemical measurements on the behavior of a BDD electrode were performed in $0.50 \mathrm{~mol} \mathrm{~L}^{-1} \mathrm{H}_{2} \mathrm{SO}_{4}$. The solution used to modify the BDD by electrodeposition was $1.0 \times 10^{-3} \mathrm{~mol} \mathrm{~L}^{-1} \mathrm{NiCl}_{2}$ in sodium acetate buffer solution ( $\mathrm{pH} 4.0)$. The passivation of the BDD electrodes was performed with phosphate buffer ( $\mathrm{pH} 7.0$ ), $0.10 \mathrm{~mol} \mathrm{~L}^{-1} \mathrm{NaOH}$ and sodium acetate ( $\mathrm{pH} 4.0)$. For the studies of electrochemical detection of carbohydrates, $0.10 \mathrm{~mol} \mathrm{~L}^{-1} \mathrm{NaOH}$ was used. The stock solutions of carbohydrates were prepared in $0.10 \mathrm{~mol} \mathrm{~L}^{-1} \mathrm{NaOH}$ at concentrations of $0.05 \mathrm{~mol} \mathrm{~L}^{-1}$.

\section{Apparatus}

Electrochemical measurements were performed on a potentiostat/galvanostat model of AUTOLAB PGSTAT 30 controlled by GPES 4.9 software. The working electrodes were constituted by plates of boron-doped diamond with an area of 1 $\mathrm{cm}^{2}$, and resistivity of 0.02 to $0.18 \Omega \mathrm{cm}$, prepared by chemical vapor deposition technique by Elementsix ${ }^{\circledR}$. The area was restricted to $0.16 \mathrm{~cm}^{2}$ in the electrochemical experiments. The reference electrode was $\mathrm{Ag} / \mathrm{AgCl}$ (in saturated $\mathrm{KCl}$ ) and the counter electrode was a platinum wire. All results were obtained using a conventional single-compartment cell.

Scanning electron microscopy (SEM) and energy dispersive $X$-ray spectroscopy $(E D S)$

Morphological characterization of BDD electrode and modified BDD electrode was performed by scanning electron microscopy and energy dispersive $\mathrm{X}$-ray spectroscopy using a cannon electron emission field effect (FEG-SEM), Model JSM $7500 \mathrm{~F}$ by JEOL.

\section{$B D D$ treatments}

The BDD electrode was subjected to anodic and/or cathodic treatments in $0.50 \mathrm{~mol} \mathrm{~L}^{-1} \mathrm{H}_{2} \mathrm{SO}_{4}$. In anodic treatment a potential of $3.0 \mathrm{~V}$ ( $v s . \mathrm{Ag} / \mathrm{AgCl}$ ) was applied for $30 \mathrm{~s}$ and in the cathodic treatment the potencial was $-3.0 \mathrm{~V}(v s . \mathrm{Ag} / \mathrm{AgCl})$ for the same interval time.

\section{Modifications of the surface of BDD}

Prior to each modification, the BDD electrodes were pretreated anodically and cathodically. Electrode modifications were carried out by electrodeposition method using $1.0 \times 10^{-3} \mathrm{~mol} \mathrm{~L}^{-1}$ $\mathrm{NiCl}_{2}$ in acetate buffer solution ( $\mathrm{pH} 4.0$ ) for $300 \mathrm{~s}$ under $-1.2 \mathrm{~V}$ (vs. $\mathrm{Ag} / \mathrm{AgCl}$ ). The formation of nickel oxide and hydroxide nickel from nickel metallic electrodeposited was carried out by successive potential scans in phosphate buffer $(\mathrm{pH} 7.0)$, acetate buffer ( $\mathrm{pH} 4.0$ ) and $0.10 \mathrm{~mol} \mathrm{~L}^{-1} \mathrm{NaOH}$. The best analytical response of the carbohydrates was obtained after submitting the nickel modified electrode to 30 cyclic scans from -0.5 to $1.0 \mathrm{~V}$, $100 \mathrm{mV} \mathrm{s}^{-1}$, for the formation of $\mathrm{Ni}(\mathrm{OH})_{2} \mathrm{NPs}$.

\section{Concentration study of carbohydrates}

For the BDD electrode as well as modified BDD electrodes, the concentration study of carbohydrates was carried by linear sweep voltammetry between -0.5 and $1.0 \mathrm{~V}, 100 \mathrm{mV} \mathrm{s}^{-1}$. The analytical curves were obtained by successive additions of each carbohydrate in $0.10 \mathrm{~mol} \mathrm{~L}^{-1} \mathrm{NaOH}$ solution.

\section{Results and Discussion}

Effect of pretreatments on the electrochemical response of the $B D D$

Cathodic and anodic pretreatments are simple and quick ways to activate the BDD electrode surface and due to gas evolution during these pretreatments, adsorbed particles on the electrode surface are removed, promoting its cleaning. Moreover, the physical and chemical properties of the BDD are affected by the polarizations. In the anodic pretreatment in acid solutions the diamond surface is oxidized and intense oxygen evolution is observed, consequently oxygen terminations are formed. These terminations are hydrophilic with positive electron affinity and low conductivity. On the other hand, during the cathodic pretreatment, intense hydrogen evolution occurs and the BDD surface is reduced, forming hydrogen terminations, which are hydrophobic with negative electron affinity and high conductivity. ${ }^{52}$

Regarding the influence of BDD preconditioning, we have studied the influence of anodic, cathodic and both pretreatments of BDD electrodes in the electrochemical detection of glucose using linear sweep voltammetry (LV). The anodic and cathodic pretreatments were performed at $3.0 \mathrm{~V}$ and $-3.0 \mathrm{~V}$ (vs. $\mathrm{Ag} / \mathrm{AgCl})$, respectively. Both were carried out for $30 \mathrm{~s}$ in $0.50 \mathrm{~mol} \mathrm{~L}^{-1} \mathrm{H}_{2} \mathrm{SO}_{4}$. BDD electrode cyclic voltammograms in an acid medium after the polarizations (not shown) showed a clean surface, with very low capacitive resistance and absence of any faradaic processes, between -0.75 and $2.35 \mathrm{~V}$. Figure 1 shows responses for BDD in $\mathrm{NaOH}$ solution after different pretreatments in the presence of $1.5 \times 10^{-3} \mathrm{~mol} \mathrm{~L}^{-1}$ of glucose. On the untreated BDD surface, no faradaic response was observed. However, when BDD is first undergone anodic pretreatment for surface cleaning ${ }^{53-55}$ and being subjected to cathodic pretreatment, the peak current for glucose oxidation increases dramatically and the oxidation peak becomes better defined. This improvement of the electrochemical response may be attributed to the formation of a hydrophilic and conductive surface due to cathodic pretreatment. ${ }^{56}$ Limit of detection (LOD), linear range, correlation coefficient $(R)$ and amperometric sensitivities (SA) for the BDD electrode were calculated and are shown in Table 1 . The catalytic superiority of BDD after two polarizations (anodic then cathodic polarization) compared to an electrode that received just one polarization or no pretreatment is confirmed by means of the 


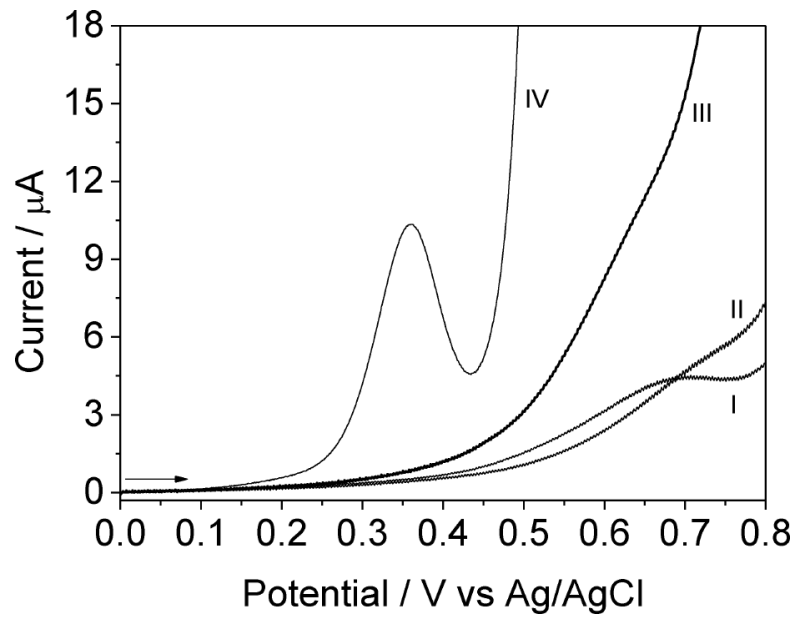

Fig. 1 Linear voltammograms obtained for BDD electrode after cathodic pretreatment (I), anodic pretreatment (II), without pretreatment (III) and after anodic and cathodic pretreatments (IV) in presence of $1.5 \times 10^{-3} \mathrm{~mol} \mathrm{~L}^{-1}$ glucose in $0.10 \mathrm{~mol} \mathrm{~L}^{-1} \mathrm{NaOH}$. Scan rate of $50 \mathrm{mV} \mathrm{s}^{-1}$.

Table 1 Analytical parameters of linear range, linearity, sensitivity and LOD for glucose using BDD electrode after different pretreatments

\begin{tabular}{|c|c|c|c|c|}
\hline $\begin{array}{c}\mathrm{BDD} \\
\text { pretreatment }\end{array}$ & Linear range $/ \mathrm{mol} \mathrm{L}^{-1}$ & $\mathrm{SA} / \mathrm{A} \mathrm{L} \mathrm{mol}{ }^{-1}$ & $R$ & $\begin{array}{l}\text { LOD }^{\text {a }} \\
\text { mol L }^{-1}\end{array}$ \\
\hline No treatment & $9.8 \times 10^{-4}-10.3 \times 10^{-3}$ & 0.002 & 0.9991 & $4.2 \times 10^{-4}$ \\
\hline Cathodic & $2.4 \times 10^{-3}-9.0 \times 10^{-3}$ & 0.002 & 0.9990 & $3.8 \times 10^{-4}$ \\
\hline Anodic & $1.5 \times 10^{-3}-11.5 \times 10^{-3}$ & 0.001 & 0.9952 & $1.0 \times 10^{-3}$ \\
\hline $\begin{array}{c}\text { Anodic and } \\
\text { cathodic }\end{array}$ & $4.9 \times 10^{-4}-11.5 \times 10^{-3}$ & 0.006 & 0.9998 & $2.6 \times 10^{-4}$ \\
\hline
\end{tabular}

a. $\mathrm{LOD}=3 \times \mathrm{SD} /$ slope.

highest SA and the lowest LOD.

\section{Nickel modified BDD electrode}

In order to improve analytical response to carbohydrates, the pretreated BDD electrode was modified with NiNP. BDD electrodes anodically and cathodically pretreated were modified with metallic NiNP by electrodeposition. The parameters for nickel modification of electrodeposition time, solution of electrodeposition and $\mathrm{pH}$ for oxidation of metallic nickel were studied in order to achieve a better response to glucose oxidation. The optimal parameters were determine to be a $1.0 \times 10^{-3} \mathrm{~mol} \mathrm{~L}^{-1}$ $\mathrm{NiCl}_{2}$ solution in acetate buffer $(\mathrm{pH} 4.0)$ and a reduction potential of $-1.2 \mathrm{~V}$ (vs. $\mathrm{Ag} / \mathrm{AgCl}$ ) applied for $300 \mathrm{~s}$. After, the nickel modified BDD electrodes were washed and placed in $0.10 \mathrm{~mol} \mathrm{~L}^{-1} \mathrm{NaOH}$ solution. Metallic nickel can be electro-oxidized to nickel hydroxide at approximately $-0.8 \mathrm{~V}$ (vs. SCE) in alkaline and aerated solution. There are two possible phases of nickel hydroxide, the hydrated $\alpha-\mathrm{Ni}(\mathrm{OH})_{2}$ and the anhydrous $\beta$ - $\mathrm{Ni}(\mathrm{OH})_{2}$, being $\beta-\mathrm{Ni}(\mathrm{OH})_{2}$ the catalytic active form favored in high electrolyte concentration. ${ }^{22}$ This form is oxidized to $\beta-\mathrm{NiO}(\mathrm{OH})$ at approximately $0.4 \mathrm{~V}$ in alkaline solutions, according to Eq. (1). ${ }^{34}$ Figure 2 shows the first and the thirtieth scan of $\mathrm{Ni}(\mathrm{OH})_{2}$ modified BDD electrode, $\mathrm{Ni}(\mathrm{OH})_{2} / \mathrm{BDD}$, in $\mathrm{NaOH}$ solution. The redox couple with $\mathrm{E}^{\mathrm{o}}=0.410 \mathrm{~V}$ refers to the process $\mathrm{Ni}(\mathrm{II}) / \mathrm{Ni}(\mathrm{III})$. An increase of

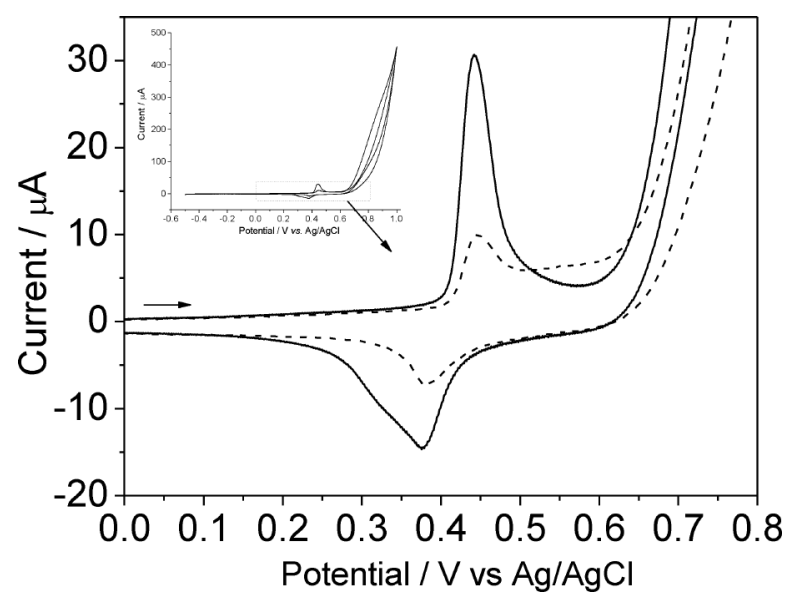

Fig. 2 First (dashed line) and thirtieth (solid line) scans for $\mathrm{Ni}(\mathrm{OH})_{2} / \mathrm{BDD}$ electrode in $0.10 \mathrm{~mol} \mathrm{~L}^{-1} \mathrm{NaOH}$; scan rate of $100 \mathrm{mV} \mathrm{s}^{-1}$.

anodic and cathodic peak currents is observed with successive scans; this is due to the entry of $\mathrm{OH}^{-}$species into the structure of $\mathrm{Ni}(\mathrm{OH})_{2} \mathrm{NPs}^{43}$

$$
\mathrm{Ni}(\mathrm{OH})_{2} \rightleftharpoons \mathrm{NiO}(\mathrm{OH})+\mathrm{H}^{+}+\mathrm{e}^{-}
$$

Chemical and morphological characterization of the BDD and nickel hydroxide modified BDD surface

The $\mathrm{Ni}(\mathrm{OH})_{2} / \mathrm{BDD}$ electrode was characterized by the techniques of scanning electron microscopy (SEM) and energy dispersive X-ray spectroscopy (EDS). The SEM was employed to observe the morphologic aspects of the modified electrodes. Figure 3 shows SEM images with 10000 times magnification EDS spectra of unmodified BDD and $\mathrm{Ni}(\mathrm{OH})_{2} / \mathrm{BDD}$.

Figure $3 \mathrm{~A}$ shows the BDD electrode surface is irregular and exhibits plateaus in its extension. According to the EDS spectrum, only carbon was identified on the BDD substrate. Figures $3 \mathrm{C}$ and $3 \mathrm{D}$ show the effective electrode modification with isolated and agglomerated hydroxide nickel spherical NPs, with size ranging from 44 to $90 \mathrm{~nm}$ in diameter. The chemical characterization proves the existence of nickel through the peaks at approximately 0.8 and $7.6 \mathrm{keV}$, and of oxygen through the peak at $0.5 \mathrm{keV}$, which are expected to modification with nickel hydroxide.

\section{Electrochemical oxidation of glucose}

In order to evaluate the electrocatalytic activity of nickel hydroxide nanoparticles toward the electrooxidation of glucose, cyclic voltammograms using $\mathrm{Ni}(\mathrm{OH})_{2} / \mathrm{BDD}$ in $0.10 \mathrm{~mol} \mathrm{~L}^{-1}$ $\mathrm{NaOH}$ in the absence and presence of $1.0 \times 10^{-3} \mathrm{~mol} \mathrm{~L}^{-1}$ glucose were obtained and are shown in Fig. 4. This figure shows that $\mathrm{Ni}(\mathrm{OH})_{2} / \mathrm{BDD}$ in an alkaline medium (dashed line) presents two distinct peaks, with $\mathrm{E}^{\circ}=0.410 \mathrm{~V}(v s . \mathrm{Ag} / \mathrm{AgCl})$, corresponding to the redox couple $\mathrm{Ni}(\mathrm{OH})_{2} / \mathrm{NiO}(\mathrm{OH})$. However, with the addition of $1.0 \times 10^{-3} \mathrm{~mol} \mathrm{~L}^{-1}$ glucose, an increase of the anodic current peak and a shift of peak potential to more positive values are observed, in addition to the disappearance of the cathodic peak related to the reduction of $\mathrm{Ni}^{3+}$ to $\mathrm{Ni}^{2+}$, which is due to the regeneration of the $\mathrm{Ni}(\mathrm{OH})_{2}$ species during the glucose oxidation reaction. This fact indicates the irreversible oxidation of glucose, and a conversion of the $\mathrm{NiO}(\mathrm{OH})$ in $\mathrm{Ni}(\mathrm{OH})_{2} \cdot{ }^{57}$ The anodic peak shift can be attributed to the diffusion limitation of glucose at the electrode surface. When voltammetric behaviors 

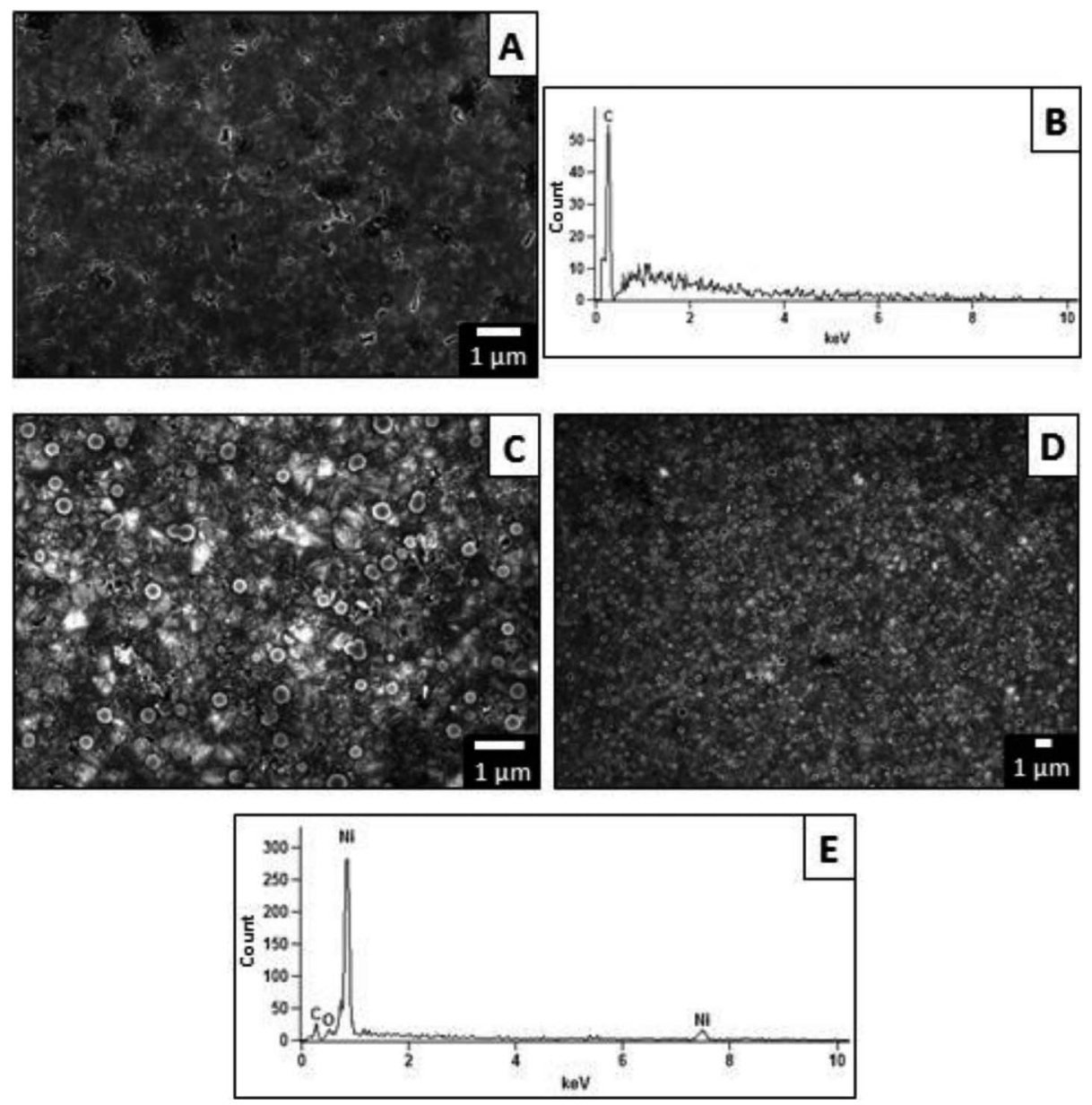

Fig. 3 SEM images: (A) unmodified BDD, magnification 10000; (C) $\mathrm{Ni}(\mathrm{OH})_{2} / \mathrm{BDD}$, magnification 10000; (D) $\mathrm{Ni}(\mathrm{OH})_{2} / \mathrm{BDD}$, magnification 3500. EDS spectra: (B) unmodified BDD; (E) $\mathrm{Ni}(\mathrm{OH})_{2} / \mathrm{BDD}$.

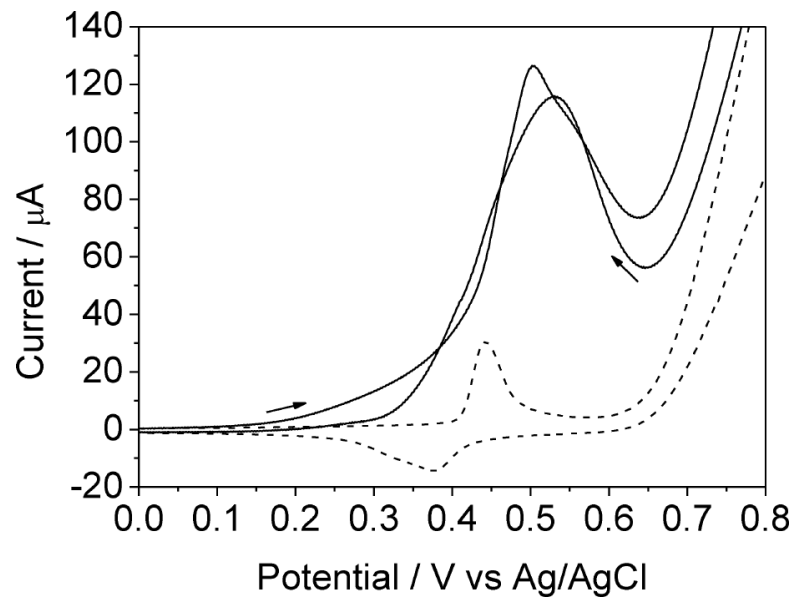

Fig. 4 Cyclic voltammograms of $\mathrm{Ni}(\mathrm{OH})_{2} / \mathrm{BDD}$ in $0.10 \mathrm{~mol} \mathrm{~L}^{-1}$ $\mathrm{NaOH}$ in presence of $1.0 \times 10^{-3} \mathrm{~mol} \mathrm{~L}^{-1}$ glucose (solid line) and in absence (dashed line). Scan rate of $50 \mathrm{mV} \mathrm{s}^{-1}$.

of glucose at $\mathrm{Ni}(\mathrm{OH})_{2} / \mathrm{BDD}$ and pretreated $\mathrm{BDD}$ are compared, a shift around $0.11 \mathrm{~V}$ for more cathodic potential is observed using the modified electrode, in addition to the pronounced increase of the peak current.

These results point to the catalytic effect of the nickel hydroxide nanoparticle that greatly facilitated the oxidation of

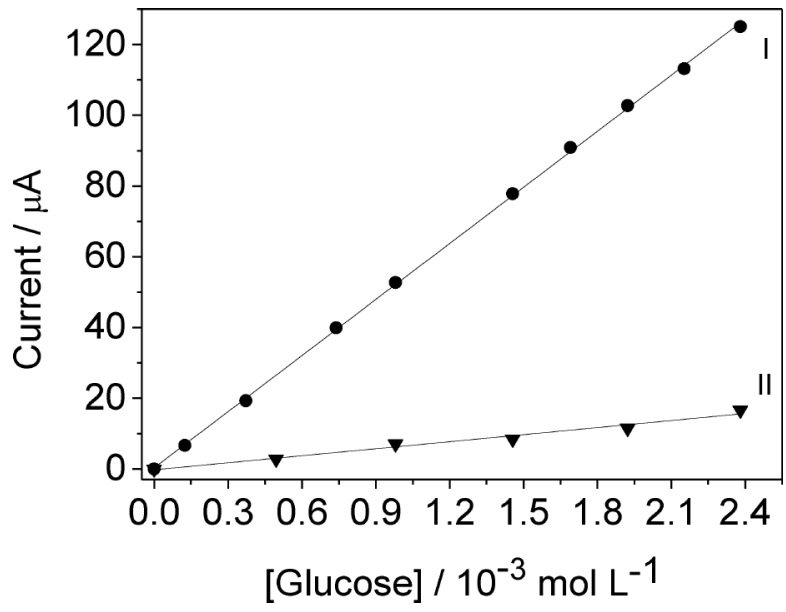

Fig. 5 Analytical curves of glucose in $0.10 \mathrm{~mol} \mathrm{~L}^{-1} \mathrm{NaOH}$ using $\mathrm{Ni}(\mathrm{OH})_{2} / \mathrm{BDD}$ electrode (I) and the pretreated unmodified BDD electrode (II). Scan rate of $50 \mathrm{mV} \mathrm{s}^{-1}$.

glucose. Figure 5 shows the analytical response of glucose using unmodified pretreated $\mathrm{BDD}$ and $\mathrm{Ni}(\mathrm{OH})_{2} / \mathrm{BDD}$ electrodes after successive additions of glucose. For the $\mathrm{Ni}(\mathrm{OH})_{2} / \mathrm{BDD}$, the peak current was linearly proportional to glucose concentration in the range between $1.3 \times 10^{-4}$ and $3.9 \times 10^{-3} \mathrm{~mol} \mathrm{~L}^{-1}$, with $R$ of 0.9999 and SA and LOD of 
Table 2 Analytical parameters for non-enzymatic electrochemical detection of glucose

\begin{tabular}{|c|c|c|c|c|}
\hline Electrode/Method & SA & $\mathrm{LOD} / \mu \mathrm{mol} \mathrm{L}-1$ & Linear range $/ \mathrm{mol} \mathrm{L}^{-1}$ & Ref. \\
\hline $\mathrm{Ni}(\mathrm{OH})_{2} / \mathrm{BDD} /$ Cyclic voltammetry & $0.053 \mathrm{~A} \mathrm{~L} \mathrm{~mol}^{-1}$ & 53 & $1.3 \times 10^{-4}-3.9 \times 10^{-3}$ & Present work \\
\hline $\mathrm{rGO} / \mathrm{Ni}(\mathrm{OH})_{2}{ }^{\mathrm{a}} /$ Amperometry & $11.4 \mathrm{~mA} \mathrm{~cm}^{-2} \mathrm{~L} \mathrm{mmol}^{-1}$ & 15 & $0.02 \times 10^{-6}-30 \times 10^{-3}$ & 58 \\
\hline NiONPs/GO/GC $/$ /Amperometry & - & 1.0 & $3.13 \times 10^{-6}-3.05 \times 10^{-3}$ & 59 \\
\hline GC/MWCNT/NiO' /Cyclic voltammetry & $0.1372 \mathrm{~mA} \mathrm{~L} \mathrm{mmol}^{-1}$ & 160 & $2.0 \times 10^{-4}-1.2 \times 10^{-2}$ & 60 \\
\hline NiNPs@P-1,5-DAN $/$ Square wave voltammetry & - & 0.252 & $0.1 \times 10^{-3}-10 \times 10^{-3}$ & 61 \\
\hline $\mathrm{Ni}(\mathrm{OH})_{2}$ modified CILE $/$ Cyclic voltammetry & $202 \mu \mathrm{A} \mathrm{L} \mathrm{mmol}{ }^{-1} \mathrm{~cm}^{-2}$ & 6.0 & $50 \times 10^{-6}-23 \times 10^{-3}$ & 62 \\
\hline $\mathrm{NiO}$ modified $\mathrm{CPE}^{\mathrm{f}} /$ Amperometry & $43.9 \mathrm{nA} \mathrm{L} \mu \mathrm{mol}^{-1}$ & 0.16 & $1.0 \times 10^{-6}-110 \times 10^{-6}$ & 63 \\
\hline $\mathrm{CS} / \mathrm{Ni}(\mathrm{OH})_{2} \mathrm{NP} / \mathrm{GC}^{\mathrm{g}} /$ Amperometry & $72 \mu \mathrm{A} \mathrm{L} \mathrm{mmol}{ }^{-1} \mathrm{~cm}^{-2}$ & - & $0.5 \times 10^{-3}-10 \times 10^{-3}$ & 64 \\
\hline NiCFPh /Amperometry & $3.3 \mu \mathrm{A} \mathrm{L} \mathrm{mmol}{ }^{-1}$ & 1.0 & $2.0 \times 10^{-6}-2.5 \times 10^{-3}$ & 65 \\
\hline Ni-BDD /Amperometry & $1.04 \mu \mathrm{A} \mathrm{L} \mu \mathrm{mol}^{-1} \mathrm{~cm}^{-2}$ & 2.7 & $5 \times 10^{-6}-10 \times 10^{-3}$ & 66 \\
\hline
\end{tabular}

a. Reduced graphene oxide matrix modified with $\mathrm{Ni}(\mathrm{OH})_{2}$ nanostructures, b. Nickel oxide nanoparticles modified electrode on the glassy carbon surface previously modified with graphene oxide, c. Glassy carbon disc electrode modified with multi-walled carbon nanotubes and $\mathrm{NiO}$, d. Nickel nanoparticles dispersed at poly1,5-diaminonaphthalene, e. Nickel hydroxide modified carbon ionic liquid electrode, f. Nano $\mathrm{NiO}$ and carbon paste, g. Nickel hydroxide nanoparticles embedded in a chitosan membrane deposited onto a glassy carbon electrode, h. Nickel nanoparticle-loaded carbon nanofiber paste electrode, i. Nickel modified BDD electrode.<smiles>O=CC(O)[C@H](O)[C@H](O)[C@H](O)CO</smiles><smiles>OC[C@H]1O[C@H](O)[C@@H](O)[C@H](O)[C@H]1O</smiles>

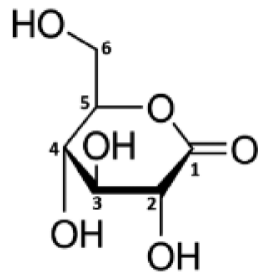

Fig. 6 Linear and cyclic structures of glucose and structure of gluconolactone.

$0.053 \mathrm{~A} \mathrm{~L} \mathrm{~mol}^{-1}$ and $5.3 \times 10^{-5} \mathrm{~mol} \mathrm{~L}^{-1}$, respectively. Comparing the results of the $\mathrm{Ni}(\mathrm{OH})_{2} / \mathrm{BDD}$ and pretreated $\mathrm{BDD}, \mathrm{SA}$ increased more than eight times and LOD decreased five times. The improvement of glucose response employing the modified BDD electrode is evident, which highlights the importance of the modification with nickel hydroxide nanoparticle for the glucose detection. The analytical parameters for glucose in the present study are compared with reported values in literature based on electroanalytical methods employing nickel modified electrodes (Table 2). ${ }^{58-66}$ Taking into account the differences between the techniques employed and the increase of surface area provided for some modifiers, the analytical parameters of $\mathrm{Ni}(\mathrm{OH})_{2} / \mathrm{BDD}$ for glucose in the present work are comparable to those reported previously. Thus, the use of the $\mathrm{Ni}(\mathrm{OH})_{2} / \mathrm{BDD}$ electrode for carbohydrate determination presented in this work is advantageous because it achieves a similar response and its preparation procedure is simple and fast when compared to other electrodes.

The electrooxidation mechanism of glucose, which is predominantly present as a ring in the $\beta$ form (Fig. 6) in an aqueous solution, and at niquel in an alkaline medium can be understood as follows: $\mathrm{Ni}(\mathrm{OH})_{2}$ is oxidized to $\mathrm{NiO}(\mathrm{OH})$; then carbohydrates are adsorbed on the surface of $\mathrm{NiO}(\mathrm{OH})$ by formation of hydrogen-bonds between $\mathrm{OH}$ groups of carbohydrate. Then, $\mathrm{NiO}(\mathrm{OH})$ removes hydrogen attached to carbon 1 of glucose (Fig. 6), forming species $\mathrm{Ni}(\mathrm{OH})_{2}$ and an intermediate organic radical, this being a chemical reaction, which is the rate-determining step in the oxidation mechanism. ${ }^{67}$ Quickly, hydroxyl ions in the supporting electrolyte complete the oxidation of intermediate organic radical and gluconolactone is formed, see the structure in Fig. 6. Electron transfer is more efficient when an $\mathrm{OH}$ group attached to adjacent carbon atom to the $\mathrm{C}=\mathrm{O}$ group is involved in adsorption. ${ }^{68}$

\section{Electrochemical oxidation of other carbohydrates}

$\mathrm{Ni}(\mathrm{OH})_{2} / \mathrm{BDD}$ was used for the electrochemical studies of galactose, mannose, rhamnose, xylose and arabinose, the most important carbohydrates present in the lignocellulosic material of sugar cane. The voltammetric behavior of these carbohydrates was studied at $\mathrm{Ni}(\mathrm{OH})_{2} / \mathrm{BDD}$ in $0.10 \mathrm{~mol} \mathrm{~L}^{-1} \mathrm{NaOH}$. All carbohydrates showed a similar voltammetric response, with reoxidation processes, increase of anodic peak current and a shift of anodic peak potential to more positive values, in addition to a decrease of cathodic peak current. The electrooxidation reactions of carbohydrates follow the same mechanism, that is, the oxidation of galactose leads to galanolactone, arabionose to arabinonalactone, manse to mannonalactone, rhamnose to rhaminonalactone and xylose to xylonolactone. ${ }^{69}$

The influence of concentration of each carbohydrate in the voltammetric behavior of $\mathrm{Ni}(\mathrm{OH})_{2} / \mathrm{BDD}$ was investigated at $50 \mathrm{mV} \mathrm{s}^{-1}$ in $0.10 \mathrm{~mol} \mathrm{~L}^{-1} \mathrm{NaOH}$. Successive additions of $0.05 \mathrm{~mol} \mathrm{~L}^{-1}$ of each carbohydrate were performed Figure 8 shows the analytical curves for glucose, galactose, mannose, arabinose, rhamnose and xylose. These curves were obtained by peak current measuring. In Table 3 , the values of LOD, linear range, SA and $R$ for carbohydrates are presented. The highest SA value for glucose when compared to other carbohydrates can be explained because the ring hemiacetal form of glucose has more $\mathrm{OH}$ groups available in relation than other carbohydrates due to the stereochemistry of these molecules. On the other hand, mannose showed the lowest SA and the worst LOD due to a lower number of hydroxyl groups 

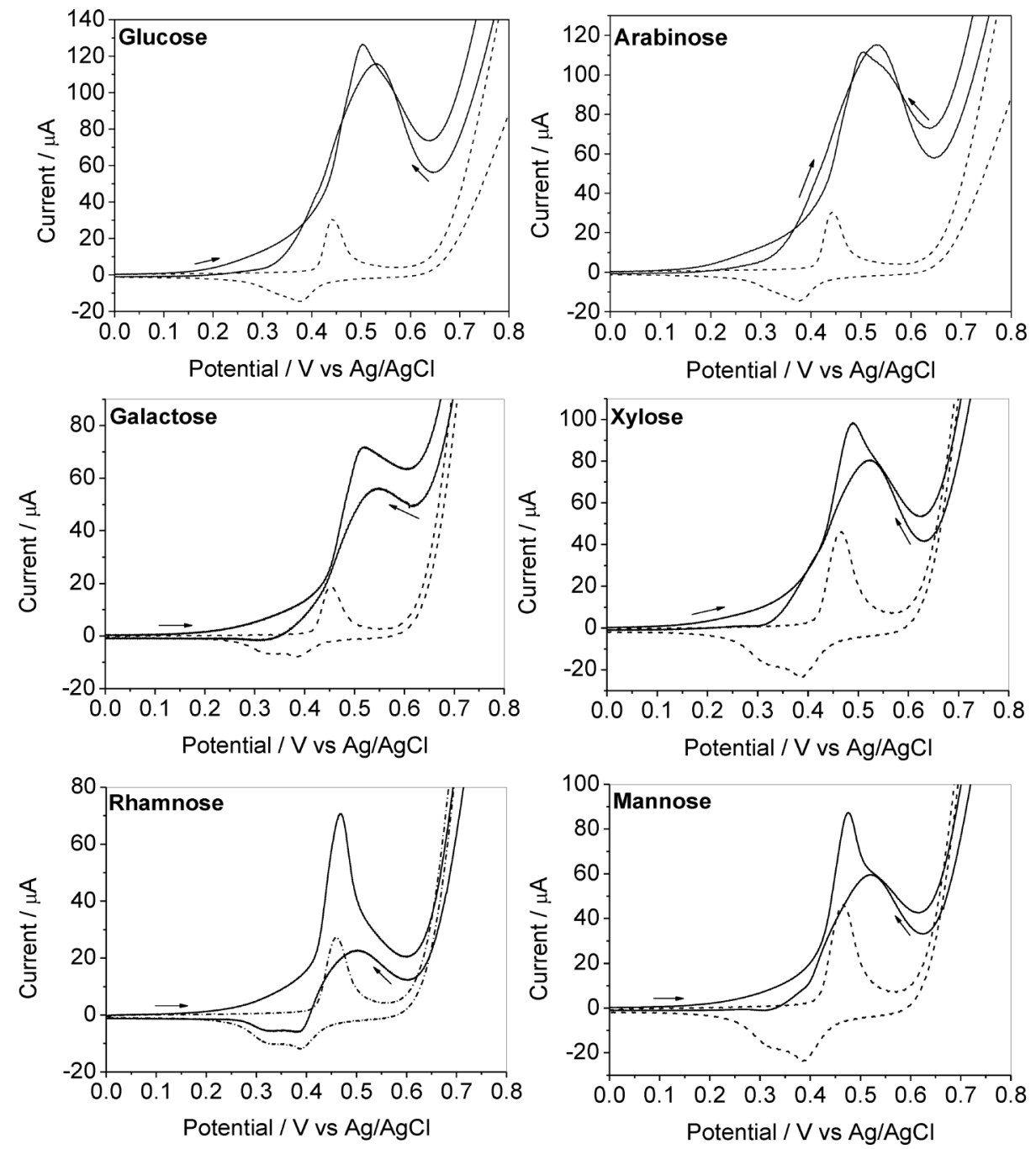

Fig. 7 Cyclic voltammograms of $\mathrm{Ni}(\mathrm{OH})_{2} / \mathrm{BDD}$ electrode in $0.10 \mathrm{~mol} \mathrm{~L}^{-1} \mathrm{NaOH}$ in the absence (dashed line) and in the presence of $1.0 \times 10^{-3} \mathrm{~mol} \mathrm{~L}^{-1}$ glucose, galactose, arabinose, mannose, rhamnose and xylose (solid line). Scan rate of $50 \mathrm{mV} \mathrm{s}^{-1}$.

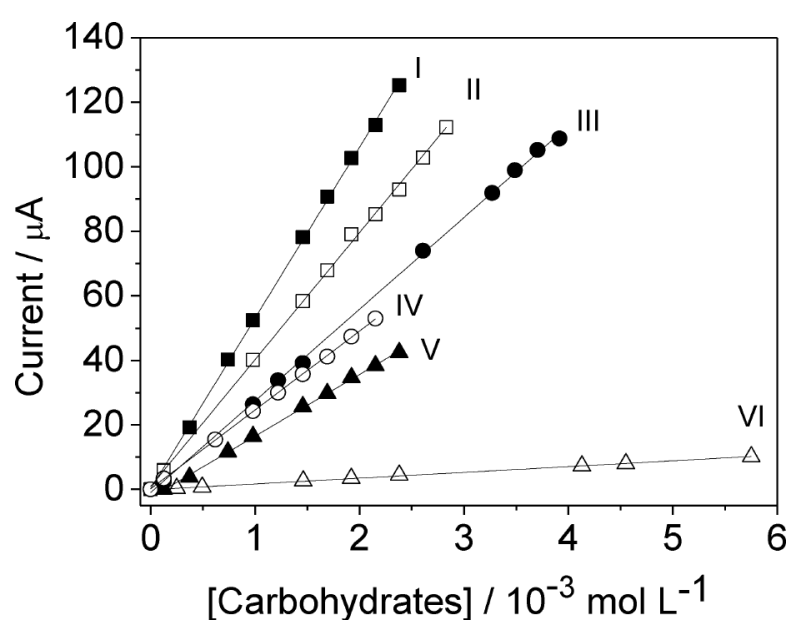

Fig. 8 Dependency between peak current and concentration of glucose (I), arabinose (II), galactose (III), xylose (IV), rhamnose (V) and mannose (VI) in $0.10 \mathrm{~mol} \mathrm{~L}^{-1} \mathrm{NaOH}$, using $\mathrm{Ni}(\mathrm{OH})_{2} / \mathrm{BDD}$ electrode.
Table 3 Analytical parameters of linear range, linearity, sensitivity and LOD for different carbohydrates at $\mathrm{Ni}(\mathrm{OH})_{2} / \mathrm{BDD}$ electrode

\begin{tabular}{lcccc}
\hline Carbohydrates & Linear range/mol L' & $\begin{array}{c}\text { SA/ } \\
\text { A L mol }^{-1}\end{array}$ & $R$ & $\begin{array}{c}\mathrm{LOD}^{\mathrm{a}} \\
\mathrm{mol} \mathrm{L}^{-1}\end{array}$ \\
\hline Glucose & $1.3 \times 10^{-4}-3.9 \times 10^{-3}$ & 0.053 & 0.9999 & $5.3 \times 10^{-5}$ \\
Galactose & $1.3 \times 10^{-4}-3.9 \times 10^{-3}$ & 0.029 & 0.9998 & $6.8 \times 10^{-5}$ \\
Mannose & $1.3 \times 10^{-4}-5.8 \times 10^{-3}$ & 0.002 & 0.9985 & $2.7 \times 10^{-4}$ \\
Rhamnose & $1.3 \times 10^{-4}-2.4 \times 10^{-3}$ & 0.019 & 0.9992 & $6.9 \times 10^{-5}$ \\
Arabinose & $1.3 \times 10^{-4}-2.8 \times 10^{-3}$ & 0.039 & 0.9991 & $8.8 \times 10^{-5}$ \\
Xylose & $1.3 \times 10^{-4}-2.2 \times 10^{-3}$ & 0.024 & 0.9999 & $2.6 \times 10^{-5}$ \\
\hline
\end{tabular}

a. $\mathrm{LOD}=3 \times \mathrm{SD} /$ slope .

available for oxidation, which contributes to a decrease in the electrochemical response. ${ }^{68}$ This contributes to an increase of adsorption on the electrode surface and the kinetics of reaction.

Recovery studies were carried out in order to evaluate the method. Recovery average values were of $(96.1 \pm 3.4) \%$ for glucose, $(97.6 \pm 1.7) \%$ for galactose, $(97.5 \pm 2.4) \%$ for mannose, $(97.6 \pm 5.3) \%$ for rhamnose, $(99.3 \pm 1.1) \%$ for arabinose and $(97.8 \pm 0.83) \%$ for xylose. 
Impedance studies for the $\mathrm{Ni}(\mathrm{OH})_{2} / \mathrm{BDD}$ electrode

Electrochemical impedance spectroscopy (EIS) is an efficient tool for studying the interface properties of surface-modified electrodes. The diameter of the semicircle in the Nyquist diagram is usually equal to the charge-transfer resistence $\left(R_{\mathrm{ct}}\right)$, which controls the charge-transfer kinetics of the redox process at the electrode interface. ${ }^{70}$

EIS experiments were performed in the frequency range from $100 \mathrm{kHz}$ to $10 \mathrm{mHz}$, at an amplitude of $5 \mathrm{mV}$ and potential of $0.46 \mathrm{~V}$. First, $\mathrm{Ni}(\mathrm{OH})_{2} / \mathrm{BDD}$ was compared to unmodified BDD, in $0.10 \mathrm{~mol} \mathrm{~L}^{-1} \mathrm{NaOH}$ the $R_{\mathrm{ct}}$ was $251.3 \mathrm{k} \Omega$ for BDD, a value much bigger than for hydroxide nickel modified electrode, for which the $R_{\mathrm{ct}}$ was $20.5 \mathrm{k} \Omega$. In $1.0 \times 10^{-3} \mathrm{~mol} \mathrm{~L}^{-1}$ glucose presence, $R_{\mathrm{ct}}$ was $17.48 \mathrm{k} \Omega$ for the bare electrode and $1.16 \mathrm{k} \Omega$ for $\mathrm{Ni}(\mathrm{OH})_{2} / \mathrm{BDD}$. These results indicate that $\mathrm{Ni}(\mathrm{OH})_{2} / \mathrm{BDD}$ offers limited resistance to charge transfer, hence promoting a very fast electron exchange rate. In other words, $\mathrm{Ni}(\mathrm{OH})_{2} / \mathrm{BDD}$ exhibits a higher catalytic activity, promoting greater interaction of the glucose molecule on the $\mathrm{Ni}(\mathrm{OH})_{2} / \mathrm{BDD}$ surface than on the unmodified diamond electrode, and these results were confirmed through cyclic voltammetric studies. $R_{\mathrm{ct}}$ values for all carbohydrates, in the same concentration, were: $1.34 \mathrm{k} \Omega$ for rhamnose and arabinose, $1.48 \mathrm{k} \Omega$ for galactose, $1.62 \mathrm{k} \Omega$ for xylose and $2.18 \mathrm{k} \Omega$ for mannose.

\section{Conclusions}

The proposed BDD electrode modification method with nickel hydroxide NPs was efficient and simple. MEV images and EDS spectra showed the effective modification of a BDD electrode with nickel hydroxide NPs. The voltammetric behavior of glucose, galactose, mannose, rhamnose, arabinose and xylose in an alkaline medium was studied. When compared to a bare BDD electrode after different pretreatments, the $\mathrm{Ni}(\mathrm{OH})_{2} / \mathrm{BDD}$ showed higher sensitivity and lower limit of detection for glucose. Thus, the $\mathrm{Ni}(\mathrm{OH})_{2} / \mathrm{BDD}$ holds great potential for employment as an electrochemical detector of carbohydrates in the lignocellulosic material of sugar cane.

\section{Acknowledgements}

The authors acknowledge financial support from Fundação de Amparo à Pesquisa do Estado de São Paulo-FAPESP (Process 2012/00258-5) and Centro Nacional de Desenvolvimento Cientifico e Tecnologico-CNPq (162208/2012-0).

\section{References}

1. H. B. Zhao, J. P. Dong, S. Y. Xing, Y. Li, J. N. Shen, and J. Q. Xu, Int. J. Hydrogen Energy, 2011, 36, 9551.

2. M. Park, T. Lee, and B. S. Kim, Nanoscale, 2013, 5, 12255.

3. L. Liao, X. J. Bian, J. J. Xiao, B. H. Liu, M. D. Scanlon, and H. H. Girault, Phys. Chem. Chem. Phys., 2014, 16, 10088.

4. J. Liu, Q. L. Zhao, C. Wu, Y. Wang, W. Wei, X. Y. Wang, and L. H. Yi, RSC Adv., 2014, 4, 17129.

5. Z. S. Li, L. Zhang, X. M. Huang, L. T. Ye, and S. Lin, Electrochim. Acta, 2014, 121, 215.

6. F. $\mathrm{Wu}, \mathrm{L} . \mathrm{G}$. Qiu, F. Ke, and X. Jiang, Inorg. Chem. Commun., 2013, 32, 5.

7. X. Chen, S. A. C. Carabineiro, S. S. T. Bastos, P. B. Tavares, J. J. M. Orfao, M. F. R. Pereira, and J. L. Figueiredo, Appl.
Catal., A, 2014, 472, 101.

8. A. Wang and H. Jing, Dalton Trans., 2014, 43, 1011.

9. H. Hosseini, H. Ahmar, A. Dehghani, A. Bagheri, A. R. Fakhari, and M. M. Amini, Electrochim. Acta, 2013, 88, 301.

10. I. S. Kucherenko, D. Y. Didukh, O. O. Soldatkin, and A. P. Soldatkin, Anal. Chem., 2014, 86, 5455.

11. X. Zhu, S. F. Wu, C. L. Li, M. T. Xu, and B. X. Ye, Int. J. Electrochem. Sci., 2014, 9, 4617.

12. F. Wang, X. W. Chen, and Z. L. Chen, Microchim. Acta, 2011, 173, 65 .

13. D. Giovanelli, N. S. Lawrence, L. Jiang, T. G. J. Jones, and R. G. Compton, Analyst, 2003, 128, 173.

14. J. B. Raoof, R. Ojani, and S. R. Hosseini, S. Afr. J. Chem., 2013, 66, 47.

15. L. H. Wang and H. H. Liu, Curr. Anal. Chem., 2013, 9, 143.

16. H. Dai, Y. L. Chen, Y. Y. Lin, G. F. Xu, C. P. Yang, Y. J. Tong, L. H. Guo, and G. N. Chen, Electrochim. Acta, 2012, $85,644$.

17. A. C. Sá, L. L. Paim, and N. R. Stradiotto, Int. J. Electrochem. Sci., 2014, 9, 7746.

18. F. W. Campbell and R. G. Compton, Anal. Bioanal. Chem., 2010, 396, 241.

19. I. M. Sadiek, A. M. Mohammad, M. E. El-Shakre, and M. S. El-Deab, Int. J. Hydrogen Energy, 2012, 37, 68.

20. F. Chekin, H. Tahermansouri, and M. R. Besharat, J. Solid State Electrochem., 2014, 18, 747.

21. A. Trunov, Electrochim. Acta, 2013, 105, 506.

22. N. R. Stradiotto, K. E. Toghill, L. Xiao, A. Moshar, and R. G. Compton, Electroanalysis, 2009, 21, 2627.

23. M. Roushani, M. Shamsipur, and S. M. Pourmortazavi, J. Appl. Electrochem., 2012, 42, 1005.

24. A. Babaei, M. Aminikhah, and A. R. Taheri, Sens. Lett., 2013, 11, 413 .

25. A. Babaei, M. Sohrabi, and M. Afrasiabi, Electroanaysis, 2012, 24, 2387.

26. A. Babaei and A. R. Taheri, Sens. Actuators, B, 2013, 176, 543.

27. W. Gao, W. W. Tjiu, J. C. Wei, and T. X. Liu, Talanta, 2014, 120, 484.

28. Z. D. Gao, J. Guo, N. K. Shrestha, R. Hahn, Y. Y. Song, and P. Schmuki, Chem.-Eur. J., 2013, 19, 15530.

29. L. C. Figueiredo-Filho, T. A. Silva, F. C. Vicentini, and O. Fatibello-Filho, Analyst, 2014, 139, 2842.

30. G. T. Liu, H. F. Chen, G. M. Lin, P. P. Ye, X. P. Wang, Y. Z. Jiao, X. Y. Guo, Y. Wen, and H. F. Yang, Biosens. Bioelectron., 2014, 56, 26.

31. L. Wang, Z. C. Hao, L. Dai, Y. H. Li, and H. Z. Zhou, Mater. Lett., 2012, 87, 24.

32. C. H. Xiang, Q. J. Xie, and S. Z. Yao, Electroanalysis, 2003, 15, 987.

33. L. A. Hutton, M. Vidotti, A. N. Patel, M. E. Newton, P. R. Unwin, and J. V. Macpherson, J. Phys. Chem. C, 2011, 115, 1649.

34. A. M. Ghonim, B. E. El-Anadouli, and M. M. Saleh, Electrochim. Acta, 2013, 114, 713.

35. S. S. Ji, Z. Yang, C. Zhang, Y. E. Miao, W. W. Tjiu, J. S. Pan, and T. X. Liu, Microchim. Acta, 2013, 180, 1127.

36. R. M. Abdel Hameed, Biosens. Bioelectron., 2013, 47, 248.

37. V. A. Kumary, T. E. M. Nancy, J. Divya, and K. Sreevalsan, Int. J. Electrochem. Sci., 2013, 8, 2220.

38. P. Subramanian, J. Niedziolka-Jonsson, A. Lesniewski, Q. Wang, M. S. Li, R. Boukherroub, and S. Szunerits, J. Mater. Chem. A, 2014, 2, 5525.

39. S.-J. Li, N. Xia, X.-L. Lv, M.-M. Zhao, B.-Q. Yuan, and H. 
Pang, Sens. Actuators, B, 2014, 190, 809.

40. B. Wang, S. M. Li, J. H. Liu, and M. Yu, Mater. Res. Bull., 2014, 49, 521.

41. K. M. Hassan, G. M. Elhaddad, and M. A. Azzem, J. Electroanal. Chem., 2014, 728, 123.

42. M. A. Kiani, M. A. Tehrani, and H. Sayahi, Anal. Chim. Acta, 2014, 839, 26.

43. A. Ciszewski and I. Stepniak, Electrochim. Acta, 2013, 111, 185.

44. Q. Cheng, C. Wu, J. Chen, Y. Zhou, and K. Wu, J. Phys. Chem. C, 2011, 115, 22845.

45. K. E. Toghill and R. G. Compton, Electroanalysis, 2010, 22, 1947.

46. V. Ganesh, S. Farzana, and S. Berchmans, J. Power Sources, 2011, 196, 9890.

47. R. E. Reim and R. M. Van Effen, Anal. Chem., 1986, 58, 3203.

48. M. Goto, H. Miyahara, and D. Ishii, J. Chromatogr. A, 1990, 515, 213.

49. Q. Chen, J. Wang, G. Rayson, B. Tian, and Y. Lin, Anal. Chem., 1993, 65, 251.

50. S. C. Rabelo, R. R. Andrade, R. Maciel, and A. C. Costa, Fuel, 2014, 136, 349.

51. G. J. M. Rocha, V. M. Nascimento, V. F. N. da Silva, D. L. S. Corso, and A. R. Goncalves, Ind. Crops Prod., 2014, 59, 63.

52. H. Girard, N. Simon, D. Ballutaud, M. Herlem, and A. Etcheberry, Diamond Relat. Mater, 2007, 16, 316.

53. S. B. Santos, C. F. Valezi, J. Scremin, C. A. R. SalamancaNeto, L. H. Dall'Antonia, and E. R. Sartori, Quim. Nova, 2014, 37, 1579.

54. E. R. Sartori, A. B. Trench, R. C. R.-Filho, and O. F.-Filho, J. Braz. Chem. Soc., 2013, 24, 1504.

55. P. B. Deroco, F. C. Vicentini, G. G. Oliveira, R. C. R.-Filho, and O. F.-Filho, J. Electroanal. Chem., 2014, 719, 19.

56. S. C. B. Oliveira and A. M. Oliveira-Brett, Electrochim. Acta, 2010, 55, 4599.

57. K. E. Toghill, L. Xiao, M. A. Phillips, and R. G. Compton, Sens. Actuators, B, 2010, 147, 642.

58. P. Subramanian, J. N.-Jonsson, A. Lesniewski, Q. Wang, M. Li, R. Boukherroub, and S. Szunerits, Mater. Chem. A, 2014, 2, 5525.

59. B. Yuan, C. Xu, D. Deng, Y. Xing, L. Liu, H. Pang, and D. Zhang, Electrochim. Acta, 2013, 88, 708.

60. M. Shamsipur, M. Najafi, and M. R. M. Hosseini, Bioelectrochemistry, 2010, 77, 120.

61. A. A. Hathoot, U. S. Yousef, A. S. Shatla, and M. A. Azzem, Electrochim. Acta, 2012, 85, 531.

62. A. Safavi, N. Maleki, and E. Farjami, Biosens. Bioelectron., 2009, 24, 1655.

63. Y. Mu, D. Jia, Y. He, Y. Miao, and H.-L. Wu, Biosens. Bioelectron., 2011, 26, 2948.

64. A. Ciszewski and I. Stepniak, Electrochim. Acta, 2013, 111, 185.

65. Y. Liu, H. Teng, H. Hou, and T. You, Biosens. Bioelectron., 2009, 24, 3329.

66. K. E. Toghill, L. Xiao, M. A. Phillips, and R. G. Compton, Sens. Actuators, B, 2010, 147, 642.

67. M. Fleischmann, K. Korinek, and D. Pletcher, J. Electroanal. Chem. Interfacial Electrochem., 1971, 31, 39.

68. G. Karim-Nezhad, M. Hasanzadeh, L. Saghatforoush, N. Shadjou, S. Earshad, and B. Khalilzadeh, J. Braz. Chem. Soc., 2009, 20, 141.

69. H. Nie, Z. Yao, X. Zhou, Z. Yang, and S. Huang, Biosens. Bioelectron., 2011, 30, 28.

70. A. Maringa, T. Mugadza, E. Antunes, and T. Nyokong, $J$. Electroanal. Chem., 2013, 700, 86. 